\title{
A Contingent Trip Model for Estimating Rail-trail Demand
}

\author{
CARTER J. BETZ*, JOHN C. BERGSTROM + \& J. M. BOWKER* \\ *U S D epartment of A griculture Forest Service, Southern Research Station, 320 Greene Street, \\ A thens, GA 30602-2044, U SA. E-mail: mbowker@fs.fed.us \\ 'D epartment of A gricultural and A pplied Economics, U niversity of Georgia, GA, U SA
}

\begin{abstract}
The authors develop a contingent trip model to estimate the recreation demand for and value of a potential rail-trail site in north-east Georgia. The contingent trip model is an alternative to travel cost modelling useful for ex ante evaluation of proposed recreation resources or management alternatives. The authors estimate the empirical demand for trips using a negative binomial regression specification. Their findings indicate a per-trip consumer surplus ranging from US\$18.46 to US\$29.23 and

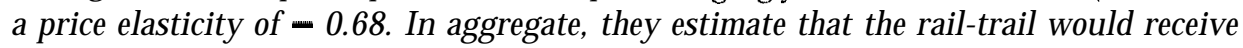
approximately 416213 recreation visits per year by area households and account for a total consumer surplus in excess of US\$7.5 million.
\end{abstract}

\section{Introduction}

Greenways are corridors of protected open space managed for conservation and recreation purposes (President's Commission on Americans Outdoors (PCAO), 1986). A primary recommendation of the PCAO during the Reagan administration was the development of a national network of greenways characterized by local, grassroots activism. Although greenways have existed in various forms for many years, it was not until the PCAO report and the founding of the Rails-to-trails Conservancy (RTC) in 1986 that greenways finally gained widespread recognition as practical and cost-efficient recreation and conservation resources. Greenways have been identified as perhaps the "last realistic option for land conservation in rapidly developing urbanized areas" (Smith, 1993, p. 3).

Rail-trails are a type of greenway in which abandoned railway rights-of-way are converted to multi-purpose public paths. The PCAO (1986, p. 104) report recommended that "thousands of miles of abandoned rail lines should become hiking, biking, and bridle paths". Since 1986, rail-trail development has increased rapidly in the USA from about 250 known rail-trails to over 1100 trails covering more than 11300 miles $(1$ mile $=1.62 \mathrm{~km}$ ) (RTC, 2001). Moreover, 1200-plus projects encompassing 19000 miles are currently in various stages of development. An informal survey conducted by the RTC found that Americans used rail-trails for recreation and transportation purposes 96 million times in 1996 (M orris, 2000).

The former Central of Georgia railway line (now Norfolk Southern) in north-east Georgia has attracted attention as an ideal setting for establishing a 
rail-trail (Bemisderfer, 1995; A thens Daily News, 1999; Carr, 2000). A 23-mile stretch of tracks near Athens, Georgia, is envisioned as both a recreation and transportation resource for local residents and a potential regional tourist attraction. Many rail-trails have considerable tourism potential, in addition to their scenic qualities, because of their connection with the national heritage of railways and the trail link they provide between communities located along the trail (Forsberg, 1994). Currently, there are only eight completed rail-trails in Georgia, comprising 93 miles (RTC, 2001). N one of the 22 proposed projects in the state includes any part of this Central of Georgia line, which parallels US Highways 441 and 129, running from Athens to Macon, Georgia.

One segment of interest to rail-trail advocates connects the towns of Watkinsville and Madison (Figure 1). Some locals refer to it as the Antebellum rail-trail (ART), after the Antebellum Trail promotional name given to US Highway 441, which it parallels, by the Georgia Department of Industry, Trade and Tourism. Despite being out of service for several years, this line has not been legally abandoned by Norfolk Southern. The proposed ART corridor has many factors necessary for a successful rail-trail. There are historic towns at either end to anchor the trail, each with thriving arts and cultural communities. The northern terminus of the ART would be located less than 10 miles from Athens, with its 30 000-plus University of Georgia students and more than 100000 metropolitan area residents. The rail-trail's attractive setting in the Georgia Piedmont includes three trestle crossings over the A palachee River and it is near many other regional recreation and tourism attractions, e.g. the Oconee National Forest and Lake Oconee, the State Botanical Gardens of Georgia and Hard Labor Creek State Park.

The basic research question motivating this study is whether a market exists for the proposed ART and, if so, what is an estimate of access value to the ART. More specifically, objectives of the research were to: (1) estimate a demand function for recreation trips to the ART; (2) examine the sensitivity of demand for ART trips to changes in the trip price and other socio-economic factors; (3) estimate the recreation use value of the resource; and (4) discuss policy implications and recommendations for further research that arise from the economic analysis. In addressing their objectives, the authors present a method that is both a lower-cost alternative to collecting data on-site and a viable option for planners seeking to address demand for currently undeveloped recreation resources.

The remainder of this paper is organized as follows. First, the authors discuss the economic theory and methods needed to estimate a demand function for the ART that allows estimation of per-trip economic benefits. Secondly, they present the research methodology, including survey design, sampling, regression model specification and functional form. Thirdly, sample statistics and empirical results of model estimation are described. Finally, the authors summarize the research results, discuss policy and management implications and offer suggestions for further research.

\section{Theoretical Background}

Rail-trails have economic value as a recreation resource if individuals are willing to pay to use them, either directly, through access fees, or indirectly, through travel expenditures necessary to reach and use the site. Other economic benefits associated with greenway and rail-trail use may include increased visitor spend- 


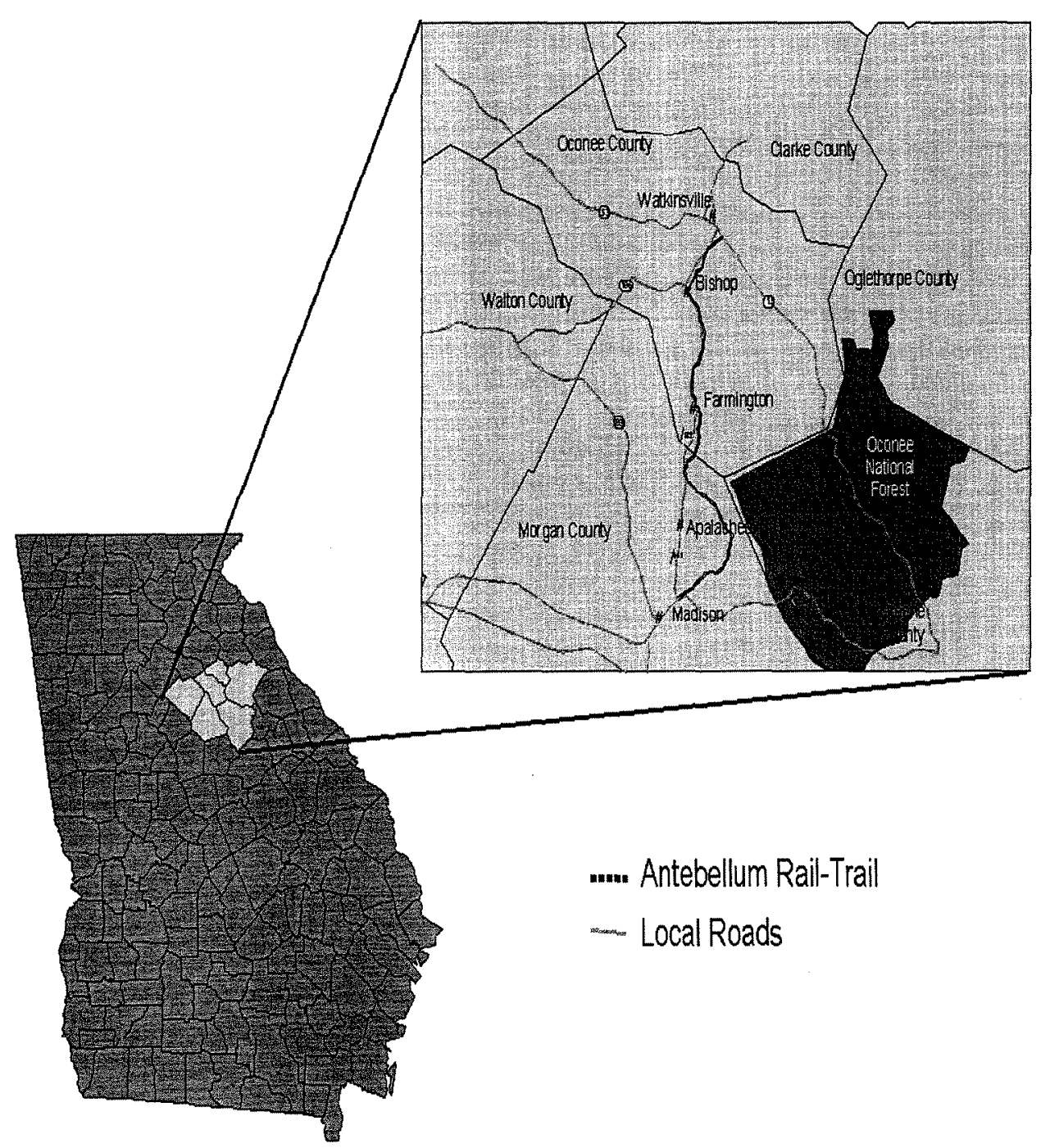

Figure 1. Rail-trail corridor in north-east Georgia.

ing and sales tax revenues, and business relocations due to enhanced community attractiveness (National Park Service, 1995). Somewhat more abstract economic and social benefits include preserving undeveloped space, enhanced community beauty, historic preservation and community pride captured by users' recreation demand for the rail-trail resource (National Bicycle and Pedestrian Clearinghouse, 1995). Alternatively, Carr et al. (1998) point out that potential economic and social costs of greenways should not be overlooked. These costs include site development and operation, decreased property tax revenues from putting land on the public roll and opportunity costs associated with using the land for other purposes.

Multiple values notwithstanding, the key to the economic feasibility of a rail-trail lies in the value associated with its direct use as a recreation resource. Recognizing this fact, the Georgia Department of Natural Resources 1992 Georgia Trails and Greenways Plan called for the assessment of recreation demand 
as an essential part of the greenways planning process (Dawson, 1995). Demand studies enable estimation of the net economic benefit to individuals for access to a recreation site. Ordinary demand functions for access to recreation sites that have no entry fee are commonly estimated using travel cost methods (Freeman, 1993; Loomis \& Walsh, 1997). The theoretical basis for travel cost derives from the basic notion of economic utility maximization subject to budget and time constraints. The method is predicated on a number of assumptions, the foremost of which is that individuals perceive and respond to changes in the travelrelated component of the cost of a trip or visit to a recreation site in the same way they would respond to a change in admission price (Freeman, 1993). H of (1993) demonstrates that this weak complementarity relationship can be exploited to derive consumer surplus (or net economic benefit) for access to a recreation site or for a given experience.

The demand for a site can be modelled as a market or aggregate demand using the zonal travel cost approach (English \& Bowker, 1996; Loomis \& Walsh, 1997). Zonal models are particularly useful in situations where data on the individuals are limited, for example when sampling is done via licence plate surveys or permits requiring very limited information (Boxall et al., 1996). More often, demand is modelled at the individual or household level through on-site or mail-back surveys (Freeman, 1993). Demand functions and consequent consumer surpluses are then estimated at the per-trip or per-person level and can be aggregated to obtain a value for the site with the appropriate independent estimate of total visits or total visitors (Leeworthy \& Bowker, 1997). Examples of applications of the individual travel cost model include Creel \& Loomis (1990), Englin \& Shonkwiler (1995) and Fix \& Loomis (1998).

Travel cost analysis, whether at the aggregate or individual scale, is usually conducted with data collected from a sample of visitors at a given recreation site. However, this restricts the method to evaluating demand for a site under the conditions at the time of the survey (Randall, 1994). This limitation precludes ex ante policy evaluation involving management alternatives that differ from the status quo. One alternative is to pool visitor data from multiple sites with differing characteristics and management regimes and employ a varying parameter travel cost model (Vaughn \& Russell, 1982). The varying parameter model is particularly well suited to addressing recreation demand and valuation related to differences in physical characteristics like water quality or catch rate.

Another alternative to the standard travel cost model is to combine the individual travel cost model with contingent behaviour questions. This hybrid is commonly called the contingent trip model (CTM) or the trip response model (TRM). The basic premise of the model is that responses to anticipated or intended trips by visitors can be treated similarly to recalled trips in creating a travel cost demand function. One of the earliest applications of this model was used to compare trip-taking behaviour and economic benefits for current versus improved water quality conditions at a beach on Lake Champlain in Vermont (Ribaudo \& Epp, 1984). More recently, this hybrid model has been used to examine trip responses to proposed changes in recreation site user fee policies (Teasley et al., 1994), to evaluate changes in fishing trip demand and economic benefits in response to proposed alternative fishery management practices (Layman et al., 1996) and to evaluate anticipated trips and consumer surplus associated with proposed wildlife and fish viewing sites on public lands(Bayless et al., 1994). 
The present study uses a variant of the CTM or TRM because the ART is a proposed recreation resource. Survey respondents were asked about intended rather than actual behaviour. Instead of 'trips', the dependent variable becomes 'expected trips' or 'anticipated trips'. Other than this distinguishing characteristic, the TRM is treated the same as any other travel cost model with the same procedures and assumptions. The general specification of the TRM demand function in this study is:

$$
Y_{i}=F\left(T C_{i}, M_{i}, S B_{i}, S E_{i}\right)+u_{i}
$$

where, for the ith individual, $Y_{i}$ is the annual quantity of intended trips to the $\mathrm{ART}, T C_{i}$ is the round-trip travel cost of one trip, $M_{i}$ is income, $S B_{i}$ is the travel cost to an alternative site with similar attributes, $S E_{i}$ is a vector representing other relevant socio-economic variables (e.g. attitudes, gender, age) and $\mathcal{u}_{i}$ is an independent and identically distributed random error term.

\section{Survey Data}

A mail survey was designed and administered to a sample of 800 north Georgia residents during the autumn of 1999. Given a restricted research budget, a limit was put on the potential geographical market to sample in light of two major considerations: (1) sufficient variation in travel distances to the rail-trail in order to estimate statistically a travel cost model; and (2) an adequate survey response rate. Previous research by Moore et al. (1994) indicated that only about $25 \%$ of visitors lived 20 or more miles from two rail-trails they studied with similar characteristics as the ART.

The selected sample region was defined as a radius of about 75 miles in all directions from the rail-trail or an approximately 1.5 hour drive. This also reflected the belief that, for this type of recreation resource, most visits would be day trips. A simple random sample of households in this region was purchased from a commercial survey-sampling firm. Survey administration followed the Dillman (1978) method of an initial mailing, a postcard reminder one week later and then a second questionnaire mailing if necessary two weeks after that. Of the 800 mailed, about 14\% were returned because of bad addresses, leaving an effective sample of 687. A total of 268 questionnaires were returned for a response rate of $39.0 \%$. Three Atlanta metropolitan counties comprised $59 \%$ of the respondents, nearly identical to their proportion of the sample. The response rate here is considerably lower than that of Siderelis \& More (1995), who obtained a rate of $79 \%$. However, their mail survey used addresses obtained directly from on-site users rather than the population at large.

The contingent trip response question was introduced with a paragraph describing the proposed trail as "most likely having a crushed stone surface suitable for bicycling and jogging". The trail was also described as a "regional resource" serving north-east Georgia as well as a potential non-motorized transportation alternative to US Highway 441. A map similar to Figure 1 was also included in the description. The text of the trip question, as it appeared in the survey, is shown in Box 1.

Each questionnaire was customized with the appropriate one-way mileage from the respondent's residence to the closer of the two rail-trail endpoints. (No major highways bisect the trail.) Respondents were not reminded of their income 
The potential "Antebellum Rail-Trail" would connect the towns of Watkinsville and Madison, Georgia. The closer of these two towns is located about miles from your residence.

If a rail-trail were developed on this abandoned rail corridor, on the average how many trips per year would you take to the rail-trail for the main purpose of using it for either recreation or transportation?

TRIPS PER YEAR (Please write in the number of trips.)

Box 1.

Table 1. Names and definitions of selected variables

\begin{tabular}{|c|c|}
\hline Variable name & Definition \\
\hline TRIPSYR & Average number of intended trips annually to ART by respondent \\
\hline MILE & Round-trip mileage from residence to closer of two rail-trail endpoints \\
\hline SUBMILE & $\begin{array}{l}\text { Round-trip mileage to a substitute rail-trail (the closer of either the Silver Comet } \\
\text { Trail in Smyrna, Georgia, or one of three Augusta, Georgia, area rail-trails) }\end{array}$ \\
\hline HHINC & Annual household income before taxes (US\$1000s) \\
\hline DPREV & $\begin{array}{l}\text { Experience binary variable where } 1=\text { respondent has used rail-trails previously for } \\
\text { recreation or transportation, } 0=\text { otherwise }\end{array}$ \\
\hline DBIKE & $\begin{array}{l}\text { Biker binary variable where } 1=\text { respondent bicycled or mountain biked often or } \\
\text { occasionally in the past } 12 \text { months, } 0=\text { respondent bicycled or mountain biked } \\
\text { seldom or never }\end{array}$ \\
\hline RURAL & Binary variable where $1=$ respondent lives in a rural county, $0=$ otherwise \\
\hline AGE & Respondent's age \\
\hline UNDER16 & Number in household under age 16 \\
\hline DCOLLEGE & Binary variable where $1=$ college graduate, $0=$ otherwise \\
\hline HHNUM & Number in household \\
\hline RACE & Binary variable where $1=$ non-white, $0=$ otherwise \\
\hline GENDER & Binary variable where $1=$ male $0=$ otherwise \\
\hline
\end{tabular}

Table 2. Descriptive statistics for selected variables

\begin{tabular}{lccccr}
\hline Variable name & $\mathrm{N}$ & Mean & $\begin{array}{c}\text { Standard } \\
\text { deviation }\end{array}$ & Minimum & Maximum \\
\cline { 1 - 2 } TRII'SYR & 268 & 1.937 & 5.10 & 0 & 50 \\
MILE & 268 & 104.6 & 34.5 & 2 & 158 \\
TIME & 267 & 143.7 & 51.3 & 10 & 274 \\
SUBMILE & 267 & 83.7 & 55.2 & 14 & 228 \\
SUBTIME & 267 & 118.8 & 68.8 & 32 & 316 \\
HHINC (US\$1000s) & 237 & 64.4 & 29.0 & 10 & 100 \\
AGE & 261 & 46.8 & 15.0 & 18 & 87 \\
DCOLLEGE & 263 & 0.563 & 0.497 & 0 & 1 \\
HHNUM & 263 & 2.56 & 1.24 & 1 & 6 \\
UNDER16 & 260 & 0.63 & 0.93 & 0 & 4 \\
DPREV & 265 & 0.204 & 0.404 & 0 & 1 \\
DBIKE & 268 & 0.228 & 0.420 & 0 & 1 \\
RURAL & 268 & 0.180 & 0.381 & 0 & 1 \\
RACE & 268 & 0.168 & 0.381 & 0 & 1 \\
GENDER & 268 & 0.634 & 0.483 & 0 & 1 \\
\hline
\end{tabular}


constraint as is sometimes the case with contingent valuation studies because they were not asked directly to make a valuation in dollars.'

Overall, the survey contained 25 questions and required about 20 minutes to complete. Questions included awareness and previous use of rail-trails in general, trail-related recreation activity participation, attitudes on selected recreation and conservation issues and, finally, a demographic profile. A follow-up to the trips response question elicited reason(s) why any respondent reported zero trips. Selected variables are reported in Table 1. Descriptive statistics are reported in Table 2. Copies of the complete questionnaire are available from the authors.

\section{Empirical Model}

Innovations in recreation trip demand modelling have improved statistical efficiency by recognizing that the dependent variable is a non-negative integer rather than a continuous variable. These count data models are estimators that account for the fact that the random dependent variable, $Y_{i}$, more closely follows a discrete rather than a continuous probability distribution. Typically, the Poisson or negative binomial distribution is selected (Greene, 2000). A number of recent studies have used count data models to estimate recreation demand (e.g. Smith, 1988; Creel \& Loomis, 1990; Yen \& Adamowicz, 1993; Siderelis \& Moore, 1995; Bowker \& Leeworthy, 1998; Fix \& Loomis, 1998; Zawacki et al., 2000).

In the only published study wherein rail-trail demand equations are estimated, Siderelis \& Moore (1995) examined and compared a number of different models and assumptions to estimate demand for three sites across the USA. Their simplest models included various functional specifications using ordinary least squares. To account for their data being zero-truncated (all respondents visited at least once), they also estimated Tobit and negative binomial models, although it is unclear whether they estimated a zero-truncated negative binomial model. While they acknowledge that on-site sampling can also lead to problems from endogenous stratification, a bias resulting from over-sampling visitors more likely to visit the site, they made no adjustments.

In a study examining mountain biking demand in Utah, Fix \& Loomis (1997) employ a zero-truncated Poisson model adjusted for endogenous stratification using a method suggested by Englin \& Shonkwiler (1995). A number of other studies have used negative binomial models instead of the Poisson. Bowker \& Leeworthy (1998) use a truncated negative binomial model to estimate natural resource-based recreation demand in the Florida Keys. They do not adjust for endogenous stratification because they claim that the heterogeneous trip lengths affect the estimator suggested by Englin \& Shonkwiler (1995). Yen \& Adamowicz (1993) and Zawacki ef al. (2000) use count data estimators to estimate the demand for sheep hunting and non-consumptive wildlife viewing, respectively. In both studies, the authors examine and compare the results of truncated and untruncated models. Both studies conclude that estimates from zero-truncated models, either Poisson or negative binomial, may be inappropriate when applied to at-large populations.

Because the data in this study derive from a sample of the population at large, on-site data problems such as endogenous stratification and zero-truncation are not encountered. Hence, negative binomial and Poisson count data models, 
without adjustment for truncation, are appropriate. The choice between negative binomial and Poisson models is based on the presence of over-dispersion, a condition found when the mean and variance of trips are unequal. The negative binomial model is considered an extension of Poisson regression that allows the variance to differ from the conditional mean (Siderelis \& Moore, 1995). Because the mean and variance of the dependent variable appear unequal (Table 2), the present authors initially selected the negative binomial model.

Following Yen \& Adamowicz (1993), the negative binomial probability distribution can be represented as:

$$
\operatorname{Prob}\left(Y_{i}=y_{i} ; y_{i}=0,1,2, \ldots\right)=\frac{\Gamma\left(y_{i}+1 / \alpha\right)}{\Gamma\left(y_{i}+1\right) \Gamma(1 / \alpha)}\left(\alpha \lambda_{i}\right)^{y_{i}}\left(1+\alpha \lambda_{i}\right)^{-\left(y_{i}+1 / x\right)}
$$

where $\lambda_{i}=\exp \left(\beta, \mathrm{TC}_{i}, \mathrm{SC}_{i}, \mathrm{M}_{i}, \mathrm{SE}_{i}, u_{i}\right)$, variables are as listed in equation (1), $\beta$ is a vector of coefficients, $\Gamma$ represents the gamma function, $\alpha$ is the overdispersion parameter, the expected value $\mathrm{E}\left(Y_{i}\right)$ is $\lambda_{i}$ and the variance $\operatorname{Var}\left(Y_{i}\right)$ is $\lambda_{i}\left(1+\alpha \lambda_{i}\right)$. An asymptotically significant $\alpha$ indicates the presence of overdispersion, making the negative binomial model appropriate. When the overdispersion parameter a is zero, both $\mathrm{E}\left(Y_{i}\right)$ and $\operatorname{Var}\left(Y_{i}\right)$ are equal to $\lambda_{i}$ and the Poisson model is appropriate (Yen \& Adamowicz, 1993). Exp $\left(u_{i}\right)$ is assumed to follow a gamma distribution with mean 1.0 and variance $\sigma$ (Greene, 2000).

Perhaps the most controversial and subjective factor for researchers using variations of travel cost modelling pertains to the choice of independent variables for model estimation. While it is commonly agreed that economic theory provides guidance for the inclusion of variables such as own price, substitute price and income (Freeman, 1993), there is considerable variation among published travel cost studies with respect to construction of the price variables. For example, Fix \& Loomis (1998) use reported travel costs including food and lodging while in transit, while Siderelis \& Moore (1995) use the product of miles driven and an estimated rate of $\$ 0.19$ per mile (all prices in US dollars). Bowker et al. (1996) report models using both methods of variable cost calculation and find no appreciable differences. Using the trip response framework, reported costs are unavailable; hence a combination of miles and a cost factor must be used. The present authors follow Englin \& Shonkwiler (1995) and specify the cost variable in miles, which can be easily scaled to dollars within the negative binomial modelling framework. Round-trip mileage (MILE) was calculated with travel direction software available on the Internet.

The opportunity cost of time is often incorporated into travel cost models. The most common approach is to use some fraction of an individual's or household's wage rate; one-third of the wage rate is a commonly used ratio (McConnell \& Strand, 1981). However, there is considerable debate about the proper wage ratio to use for valuing time in travel cost models, or whether to value time at all for shorter trips (Freeman, 1993). Siderelis \& Moore (1995) use an instrumental variable approach and determine different wage ratios for each of the three rail-trails in their study. Alternatively, Fix \& Loomis (1998) include time as a separate regressor. In the present study, the authors found time and distance to be highly correlated and opted to exclude travel time from the model.

The authors selected two existing rail-trails as substitutes for the ART. The Silver Comet Trail in suburban Atlanta was judged to be the closest substitute 
site for the large majority of the study's sample; the remainder lived closer to a rail-trail in suburban Augusta, Georgia. It was assumed that if an individual sought out information on rail-trails in general, information on the Silver Comet and Augusta rail-trail would be readily available. Round-trip substitute site mileage (SUBMILE) was constructed for each zip code to substitute site combination.

While many recreation demand studies, including Fix \& Loomis (1998) and Siderelis \& Moore (1995), do not find income to be a statistically significant variable, the authors chose to include household income (HHINC) for theoretical reasons. In particular, income imposes a budget constraint on consumption that should be accounted for in demand functions. In addition to income, Loomis \& Walsh (1997) list a number of candidate socio-economic variables that may be included in travel cost demand models, including age, education, race, gender, occupation and others. Bayless et al. (1994) included a total of nine socioeconomic variables in their TRM model. After dropping income because of the lack of statistical significance, Fix \& Loomis (1998) included age as the only socio-economic demand shifter, while Siderelis \& Moore (1995) use a variable reflecting the age composition of each visitor group. Both studies found mixed results with age variables. Given these results, and no clear theoretical guidance, the present authors chose to include the age (AGE) of the respondents.

Siderelis \& Moore (1995) use binary variables to differentiate users by biking and walking activities. The authors follow this approach by using a dummy variable (DBIKE) for respondents who biked on a regular basis. The authors also included binary variables to indicate previous experience with rail-trails (DPREV) and whether the individual lived in a rural county (DRURAL). A number of studies have found experience, either with a specific site or in reference to a given activity, to be significant in explaining recreation behaviour (Schreyer et al., 1984; Bowker \& Leeworthy, 1998; Furuseth \& Altman, 1991). The present authors included the rural variable to account for possible differences in tastes and preferences between rural and suburban residents. Moreover, given that the rail-trail would be situated in a rural area but the majority of users in the sample are from surrounding suburban areas, the authors felt it important to see if differences in tastes and preferences existed, as these could have important policy ramifications.

\section{Results}

Table 2 lists summary statistics for a number of variables in the questionnaire related to the empirical model. Mean annual household income for the sample was about $\$ 64400$. This compares favourably to 1999 estimates of mean household income in Georgia of $\$ 70500$ (Woods \& Poole Economics, Inc., 1997) and mean household income of $\$ 60200$ for the 41 sample counties (1999 dollars, US Census Bureau, provided by Survey Sampling, Inc.). Sample proportions for gender and race differed considerably from those reported in the 2000 census for Georgia. Males represented $63 \%$ of the present sample, while males make up slightly over $49 \%$ of the state's population. Similarly, non-whites comprised $17 \%$ of the sample, while making up about 35\% of the state's population. Average age of the survey respondents was about 47 years, ranging from 18 to 87 . The mean household size of respondents was about 2.6. 
Regarding individual tastes and preferences, about $20 \%$ of the sample had previous experience with rail-trails. About $31 \%$ of the sample said they were familiar with the term 'rail-trail' before receiving the survey. Nearly $47 \%$ responded that they had previously used a more generic 'greenway' trail. Almost three-fourths of the respondents were occasional or frequent walkers, regardless of location. A much lower proportion, $23 \%$, rode mountain bikes or road bicycles either occasionally or often in the past year. Forty-one per cent of the sample expressed strong support, in a Likert-type question, for converting abandoned railways to public use trails in their communities.

Table 2 also includes variables used for demand modelling. Respondents anticipated, on average, taking fewer than two trips annually to the ART. Just under $99 \%$ of respondents reported 12 or fewer trips per year, while no one reported 13 to 29 trips per year. A pproximately $1 \%$ of the sample, four observations, reported expecting to make from 30 to 50 trips. About $38 \%$ of respondents said they would take zero trips to the rail-trail. More than half of these $(56 \%)$ said they might visit the ART, but would not make any trips specifically to do so. Time and cost constraints were the next most common reason for a zero-trips response, about $26 \%$. The mean distance of all survey respondents from the rail-trail was about 52 miles one-way. Travel time to the rail-trail averaged about 72 minutes one-way with a high of more than two hours. Average distance to either substitute site was 42 miles one-way.

Results from the estimated trip response demand model are presented in Table 3. Model estimation was done using LIMDEP software (Greene, 1995). Following Englin \& Shonkwiler (1995), the estimation sample was trimmed to exclude four observations deemed extreme because they exceeded the sample mean for anticipated trips by more than five standard deviations. Negative binomial parameter estimates and marginal effects, calculated at sample means, are reported with appropriate asymptotic t-statistics, and significance levels. The estimate of the over-dispersion parameter (ALPHA) is highly significant ( $P$ values are reported in the centre column of Table 3 ), indicating that the negative binomial model is superior to the Poisson model. Mean annual visitation predicted by the estimated model is 1.367 trips.

The distance variable (MILE), which serves as a proxy for travel cost, is significant, with a negative sign consistent with a downward-sloping demand

Table 3. Trip response model maximum likelihood parameter estimates and marginal effects: dependent variable = intended trips, $n=249$

\begin{tabular}{lcccc}
\hline Variable & Parameter estimate & $P(|T|>t)$ & Marginal effect \\
\cline { 3 - 4 } Constant & 1.111 & $(2.379) "$ & 0.017 & 1.519 \\
MILE & $-0.0065(-2.357)$ & 0.018 & -0.0089 \\
SUBMILE & -0.0011 & $(-0.859)$ & 0.498 & 0.0015 \\
HHINC & -0.0019 & $(-0.887)$ & 0.486 & -0.0026 \\
AGE & $-\mathbf{0 . 0 0 3 6}$ & $(-\mathbf{0 . 6 7 8 )}$ & 0.498 & -0.0049 \\
DBIKE & 0.4952 & $(2.428)$ & 0.019 & 0.6740 \\
DPREV & 0.3408 & $(1.887)$ & 0.099 & 0.4657 \\
DRURAL & 0.1187 & $(0.588)$ & 0.631 & 0.1623 \\
ALPHA & 0.6811 & $(4.812)$ & 0.000 & \\
\hline
\end{tabular}

'Asymptotic t-statistic. 
curve. Counter to economic theory, the household income variable, HHINC, had a negative although insignificant coefficient. One possible reason is that people of similar incomes choose similar recreation pursuits. However, given the range of incomes in the study, one might argue that people of all incomes partake of rail-trail recreation. Multicollinearity is another possible reason, which would cause inflated coefficient variance; however, correlation coefficients between income and other explanatory variables show no apparent problems. Bowker \& Leeworthy (1998) note that insignificant income coefficients are not uncommon in recreation demand studies. Both Siderelis \& Moore (1995) and Fix \& Loomis (1998) exclude income from their reported demand models.

The substitution variable, SUBMILE, was also insignificant. A number of factors could account for this. While the authors chose two existing rail-trail sites as likely substitutes for the ART, it is possible that individuals would substitute alternative locations offering similar activity venues, like state and local parks, or that individuals would substitute different activities altogether. Fix \& Loomis (1997) were more successful in identifying substitute variables. This is probably related to the fact that the demand function they modelled was for a special location (Moab), with a very specialized activity (mountain biking). Alternatively, Siderelis \& Moore (1995) could not find an adequate substitute for any of their rail-trail sites.

The binary variable identifying bikers $(\mathrm{DBIKE}=1$ ) was significant with a positive sign. This indicates that when other factors are equal, bikers would demand more trips than non-bikers. The authors obtain a similar result for individuals who claim to have previously used a rail-trail (DPREV $=1$ ). This result corroborates previous recreation research suggesting that experience affects recreation choices and behaviour.

A final variable in the model was DRURAL, indicating whether the individual lived in a rural area. The coefficient for this variable was positive, suggesting that rural dwellers would be more likely to use the ART. However, the result was not statistically significant. The lack of a significant difference between rural and non-rural suggests that development of a rail-trail in a rural area would not necessarily lead to excessive use by outsiders.

\section{Economic and Use Measures}

Two important economic policy measures can be derived from the estimated demand model: price elasticity of demand ( $\zeta)$ and consumer surplus (CS). Price elasticity is a unitless measure of demand response to changes in a good or service's price. It is defined as the percentage change in quantity demanded divided by the percentage change in the price. Price elasticity is negative because of the inverse relationship between price and quantity. A unitary elasticity implies that price and quantity change in the same proportion. Price elasticity typically encountered in recreation demand studies ranges from about -0.2 to - 2.0 (Loomis \& Walsh, 1997).

Within the negative binomial model's semi-log form, price elasticity is derived as $\zeta=\beta_{\mathrm{tc}} \times \mathrm{TC}$, where $\beta_{\mathrm{tc}}$ is the estimated coefficient on the travel cost variable and TC is travel cost. As distance or travel cost increases so does the estimated elasticity. At the sample mean for roundtrip distance of 104.6 miles, $\zeta=-0.68$. Elasticities calculated from the Siderelis \& Moore (1995) study, using the negative binomial estimates, range from -0.207 for the suburban Lafayette 
Morgana Trail in Oakland, California, to -0.235 for the St Mark's Trail in northern Florida, to $\mathbf{- 0 . 4 3 0}$ for the Heritage Trail in rural lowa.

While the present authors' results can be termed moderately inelastic, they are more elastic, and hence price sensitive, than those of Siderelis \& Moore (1995). The differences could be due to a number of reasons, the most basic being that there are inherent differences in surveyed populations, with the authors' results suggesting that general public demand for rail-trail use is more price sensitive than the on-site user population examined by Siderelis \& Moore (1995). Certainly, the authors' sample of potential users would not have developed any affinity or place attachment effects that might make their demand more price inelastic. A nother explanation for the elasticity differences is that demand and supply relationships may have changed somewhat since Siderelis \& Moore's (1995) data were collected in 1991. Siderelis \& Moore (1995) state that suitable substitute sites were not readily identifiable at the time of their work. Also, the higher proportion of local users in their study, coupled with the fact that the formula for elasticity in count models forces elasticity to increase as distance (cost increases), could be a factor. Finally, a basic methodological difference stems from the present authors' use of the trip-response method versus Siderelis \& Moore (1995) using on-site surveying and standard travel cost models.

A practical implication of the inelastic price elasticity pertains to the implementation of access or parking fees that could be used to supplement public funding for trail maintenance. For example, using a per-mile cost of 12 cents,' sample average travel cost is $\$ 12.56$ and $\zeta=--0.681$. Price would have to rise to approximately $\$ 18.46$ before the unitary portion of the demand curve was reached, implying that entry or parking fees of up to $\$ 5.90$ would depress visitation by a lesser percentage than the increase in price and consequently lead to increases in revenue. This is conditioned by the assumption that users responded similarly to the on-site fees as to any other increase in travel cost.

The other important measure gleaned from demand estimation is CS or net economic value. It expresses a non-observable measure of utility in terms of dollars and is interpreted as willingness to pay (WTP) for access to the site over and above the necessary travel cost (Bergstrom, 1990; Siderelis \& Moore, 1995). Typically, for recreation applications, use is measured in visits, trips or recreation days. For day use sites, these measures are equal. Hence, for economic valuation it is convenient to derive consumer surplus on a per-trip basis. Using the negative binomial specification, per-trip consumer surplus is calculated as CS $=-1 / \beta_{\text {tc }}$ (Creel \& Loomis, 1990). Unlike the calculated price elasticity, CS per trip varies with assumed per-mile travel cost. Using 12 cents per mile, per-trip consumer surplus for access to the ART is $\$ 18.46$. Following Siderelis \& Moore (1995), using 19 cents per mile, CS per trip is $\$ 29.23$. The latter estimate falls within the range of estimated surpluses $(\$ 9.56, \$ 30.18, \$ 49.78)$ for the three rail-trails (Lafayette-Morgana, Heritage, St Mark's) in their study.

CS estimates can be of use to regional, state and local planners in estimating aggregate benefits necessary for a cost-benefit analysis of the ART. For example, aggregate annual net economic value can be estimated by combining consumer surplus per trip (\$18.46) with annual visitation. Visitation can be approximated by combining average predicted annual trips (1.367), the product of the number of households in the 75-mile study radius (780 697) and the percentage of households responding to the survey (0.39). This yields an estimated 416213 household visits with aggregate annual benefits totalling over $\$ 7.5$ million. 
Previous studies have shown evidence that WTP stated in contingent valuation surveys may over-estimate actual WTP, including applications to greenway projects, of which rail-trails are a special case (Lindsey \& Knaap, 1999). The observed differences between stated WTP and actual WTP observed in previous studies are often relatively small, suggesting that in well-designed contingent valuation studies, stated WTP provides a reasonable approximation of actual WTP (Mitchell \& Carson, 1989; Boyle \& Bergstrom, 1999). To the present authors' knowledge, previous validation studies have not been conducted to compare stated trip responses to actual trip responses. If the results of validation studies comparing stated and actual WTP carry over to trip response studies, it is possible that the authors' estimates of stated mean trips and WTP (CS) per person associated with the ART derived from the trip response model overestimate actual mean trips and WTP per person. More research is needed to test and confirm the extent to which stated trip responses and actual trip responses may differ.

Because of the possibility that stated trip responses may over-estimate actual trip responses, the present estimate of aggregate annual benefits includes several conservative use assumptions. First, the authors assumed that neither the non-respondents nor those beyond the imposed 75-mile radius would take trips to the ART. Secondly, the study is focused at the household level, and hence may under-count total visits, which could include additional household members. Thirdly, the estimate is based on the assumption that local demand would not be further stimulated by the existence of the site. In addition, the wording of the trip response question does not explicitly mention fitness as a reason for taking rail-trail trips, because the authors assumed that fitness was subsumed in recreation. However, as suggested by one of the reviewers, if some respondents excluded fitness trips because of the particular wording of the trip response question, the expected effect would be to under-estimate use. This effect, if indeed present in the trip response model results, would also help to offset a potential tendency for respondents to over-estimate stated trips as compared to actual trips.

A final potential source of error pertains to sample versus population proportions. The sample contained higher proportions of whites and males than recent census figures for the area. Also, a disproportionately high proportion of respondents, $56 \%$, reported having at least four years of college. These proportions are not unlike those reported by Furuseth \& Altman (1991). Because it has been documented that white males are more likely to engage in trail-based activities than other race/ gender combinations (Bowker et al., 1999), the authors' estimate of 1.367 visits per household, even in the absence of hypothetical bias, would not be appropriate for extrapolation across all area households. Rather, a segmented procedure, albeit ad hoc, as the authors followed with respondents and non-respondents, should be used. A related alternative for future research would be to explore the development of two-stage procedures combining sample and non-sample information to first predict whether a household would be a potential market entrant, and if so, how many trips they would take. Such models have been suggested for use in recreation demand modelling to mitigate the problem of non-response bias.

These caveats notwithstanding, the authors' visitation estimate appears to be in line with a number of previous studies. For example, Hunter \& Huang (1995) report use estimates from a number of studies of multipurpose trails ranging 
from over 2000 per day in metropolitan New York to 200 per day outside Providence. On the same trails studied by Siderelis \& Moore (1995), Moore et al. (1994) report estimated annual user densities ranging from 52632 per mile for the urban Lafayette-M organa Trail to 5192 for the Heritage Trail in rural Iowa and 10625 for the St Mark's Trail proximal to a major university in Florida. In a study of the N orth Central Rail Trail outside Baltimore, PFK Consulting (1994) reported an annual visitation estimate of 457540 on the 20-mile length of the trail. The present authors' estimate is also relatively close to Lindsey's (1999) visitation estimates of 456600 and 379500 for two sections of the Monon Trail in Indianapolis.

\section{Summary and Conclusions}

This study examined the demand for and value of access to a proposed rail-trail that would result from conversion of a 23-mile-long stretch of abandoned railway corridor in north-east Georgia to a public use trail that prohibits motorized vehicles. Rail-trails have been touted for providing much-needed close-to-home recreation resources that support popular activities like walking, bicycling, in-line skating and wildlife viewing. In many cases, they are also considered important regional tourism attractions that bring in significant amounts of visitor spending to local economies.

The authors used a contingent trip approach, a stated preference variant of the travel cost method, to estimate net benefits or consumer surplus values associated with rail-trail trips. This approach provides a cost-effective alternative to on-site sampling and more traditional travel cost modelling in a number of ways. First, it allows planners to obtain demand and value information about a potential site or management alternative at a given site for which comparable studies do not exist. Secondly, it incorporates information from non-users into the formulation of the demand model, thus circumventing problems of zerotruncation and endogenous stratification (Siderelis \& Moore, 1995).

Although the CTM or TRM has been applied in past studies, more research using this type of hybrid model is recommended to verify its utility and validity. The authors' findings of per-trip consumer surplus and price elasticity suggest that the per-trip economic measures are reasonable. These results notwithstanding, there are a number of limitations and caveats that must be mentioned. First, the CTM is still subject to criticism associated with its intended behaviour underpinning. Nevertheless, techniques based on hypothetical or intended behaviour are prevalent in marketing research conducted in the private sector. However, there exists an important need to develop comparison experiments whereby the aggregate use estimates developed from CTM models can be validated against actual counts. Secondly, with a response rate of about $40 \%$, the possibility of non-response bias is a concern. In this study, income levels of sample respondents were reasonably close to census figures for the region. However, the minorities are under-represented, while males and college graduates are over-represented.

The most salient policy implication from this study is the basic fact that a discernible demand for the proposed ART would exist with considerable economic value. Identification of tourism markets is critical because they represent the demand side of the industry, without which there would be no need for tourism suppliers or producers. It is expected that the ART's potential market 
would consist primarily of regional day users. There was some evidence, however, of potential users living beyond a one- to two-hour drive, as far away as 200 miles one-way. This has important implications with respect to tourism development objectives, as the ART would possess attributes and characteristics similar to other rail-trails in the USA that have proven to be successful tourism attractions.

The estimates of aggregate value would prove useful to a cost-benefit analysis assessing the economic feasibility of converting the rail corridor to a public use trail. If costs exceeded the most conservative value estimate, decision makers would need to weigh the credibility of the other estimates in the process. The authors did not consider the cost side of the equation, but an accounting of acquisition, development, maintenance, economic and other costs to convert the corridor into the ART would be fairly straightforward.

Model findings might also have implications for the marketing and management of the proposed ART. One is an improved understanding of the potential users. For example, none of the basic socio-economic variables was statistically significant, indicating that among respondents, no specific demographic segment would more likely to frequent the rail-trail. However, whites, males and college graduates were over-represented in the sample, suggesting that results from a single-stage model should be interpreted cautiously. More research is needed before conclusions can be drawn about the type of individuals that would characterize the market. The cost variables show that users do respond to price at less than unitary elasticity. This is important information if user fees were ever considered. Not surprisingly, the more avid potential users would be bicyclists and those with previous rail-trail experience. This knowledge of users could prove useful toward building constituent groups and public support.

More economic research on the demand for and valuation of rail-trails is warranted as these dormant resources are considered for conversion to viable recreation destinations. As a relatively new and increasingly popular type of recreation resource, additional, credible economic information about the benefits and costs of these resources is needed. Very little previous work addressing economic values of rail-trails has been accomplished. More is needed for comparative purposes. More research has evaluated the more generic 'greenways', especially in urban areas. While similar in many respects, there are distinctive differences between rail-trails and the more general greenways, including types of surfaces, lengths, grades, environments and settings. All rail-trails are also considered 'greenways', but the reverse is not true. Research into user preferences for the various attributes of greenways and rail-trails would help improve understanding of economic value and demand. Of particular interest would be knowing more about the differences in attributes (beyond just their location) between greenways and rail-trails that are recognized as tourist attractions and those that are not. More information on the characteristics of individuals who demand rail-trail trips, perhaps through some kind of clustering technique that examined demographics with attitudes and desired attributes, would also prove helpful in improving rail-trail demand models.

\section{Acknowledgements}

This research benefited from the helpful comments of Dr Greg Lindsey and the journal's reviewers. The authors are also grateful for the support of the Georgia 
Agricultural Experiment Station and Southern Research Station of the US Department of Agriculture Forest Service. Responsibility for both the views expressed in this paper and any remaining errors rests with the authors.

\section{Notes}

1. As a matter of protocol, many contingent valuation questionnaires include a statement reminding respondents to consider their budget constraint when answering willingness-to-pay questions. We did not include such a statement in our questionnaire. We assume that when answering the trip response question, respondents to our survey considered their budget constraints as well as substitutes. An interesting future experiment would be to test whether or not budget constraint reminders result in statistically significant changes in mean responses to trip response questions.

2. Federal guidelines recommend using the most current figures from the U.S. Department of Transportation or American Automobile Association (AAA) on the average per-mile cost of operating automobiles (Loomis \& Walsh, 1997). AAA's 1998 edition of Your Driving Costs cites an average operating cost of $\$ 0.12$ per mile for an 8-cylinder, I-door passenger sedan and the same cost for a 6-cylinder, 2-door sport utility vehicle.

\section{References}

Athens Daily News (1999) Athens-to-Madison rails-to-trails project could pay, Editorial, 29 June Bayless, D.S., Bergstrom, J.C., Messonnier, M.L. \& Cordell, H.K. (1994) Assessing the demand for designated wildlife viewing sites, Journal of Hospitality and Leisure M arketing, 2(3), pp. 75-93.

Bemisderfer, T.R. (1995) Using abandoned railroad rights-of-way in rural landscapes as nature conservation and linear recreation areas, unpublished master's thesis (Athens, GA, Department of Landscape Architecture, University of Georgia).

Bergstrom, J.C. (1990) Concepts and measures of the economic value of environmental quality: a review, Journal of Environmental M anagement, 31, pp. 215-228.

Bowker, J.M. \& Leeworthy, V.R. (1998) Accounting for ethnicity in recreation demand: a flexible count data approach, Journal of Leisure Research, 30(1), pp. 64-78.

Bowker, J.M., English, D.B.K. \& Donovan, J.A. (1996) Toward a value for guided rafting on Southern rivers, Journal of A gricultural and Applied Economics, 28(2), pp. 423432.

Bowker, J.M., English, D.B.K. \& Cordell, H.K. (1999) Projections of outdoor recreation participation to 2050, in: H. K. Cordell (Ed) Outdoor Recreation in American Life: A N ational Assessment of Supply and Demand Trends (Champaign, IL, Sagamore Publishing).

Boxall, P.C., McFarlane, B.L. \& Gartrell, M. (1996) An aggregate travel cost approach to valuing forest recreation at managed sites, Forest Chronicles, 72, pp. 615-621.

Boyle, K.J. \& Bergstrom, J.C. (1999) Doubt, doubts, and doubters: the genesis of a new research agenda?, in: I. J. Bateman \& K. G. Willis (Eds) Valuing Environmental Preferences: Theory and Practice of the Contingent Valuation Method in the US, EU and Developing Countries ( $\mathrm{N}$ ew York, Oxford University Press).

Carr, G. (2000) Rails to trails keeps the faith, Flagpole M agazine, 26 January.

Carr, J.B., Delhomme, K.A. \& Johnson, L.S. (1998) Assessing Community Impacts from Greenways: Recommendations for Identifying, $M$ easuring, and Estimating the Benefits and Costs of Corridors (Tallahassee, FL, Center for International Public Management, Inc. \& Florida Department of Environmental Protection, Office of Greenways and Trails).

Creel, M.D. \& Loomis, J.B. (1990) Theoretical and empirical advantages of truncated count data estimators for analysis of deer hunting in California, American Journal of Agricultural Economics, 72, pp. 434441.

Dawson, K.J. (1995) A comprehensive conservation strategy for Georgia's greenways, landscape and Urban Planning, 33, pp. 2743.

Dillman, D.A. (1978) $M$ ail and Telephone Surveys: The Total Design M ethod (New York, Wiley).

Englin, J. \& Shonkwiler, J.S. (1995) Estimating social welfare using count data models: an application to long-run recreation demand under conditions of endogenous stratification, Review of Economics and Statistics, 77, 104-112.

English, D.B.K. \& Bowker, J.M. (1996) Sensitivity of whitewater rafting consumer's surplus to pecuniary travel cost specifications, Journal of Environmental Management, 47, pp. 79-91. 
Fix, P. \& Loomis, J.B. (1997) The economic benefits of mountain biking at one of its Meccas: an application of the travel cost method to mountain biking in Moab, Utah, journal of Leisure Research, 29(3), pp. 342-352.

Fix, P. \& Loomis, J.B. (1998) Comparing the economic value of mountain biking estimated using revealed and stated preference, Journal of Environmental Planning and M anagement, 41(2), pp. 227236.

Forsberg, M. (1994) Rails-to-trails, Nebraskaland, June, pp. 44-55.

Freeman III, A.M. (1993) The Measurement of Environmental and Resource Values (Washington, DC, Resources for the Future).

Furuseth, O.J. \& Altman, R.E. (1991) Who's on the greenway: socioeconomic, demographic, and locational characteristics of greenway users, Environmental M anagement, 15(3), pp. 329-336.

Greene, W.H. (1995) LIMDEP, V ersion 7.0 (Plainview, NY, Econometric Software, Inc.).

Greene, W.H. (2000) Econometric Analysis, 4th edition (Englewood Cliffs, NJ, Prentice-Hall).

Hof, J. (1993) Coactive Forest M anagement (New York, Academic Press).

Hunter, W.W. \& Huang, H.F. (1995) User counts on bicycle lanes and multiuse trails in the United States, Transportation Research Record, 1502, pp. 45-57.

Layman, R.C., Boyce, J.R. \& Criddle, K. (1996) Economic valuation of the Chinook salmon sport fishery of the Gulkana River, Alaska, under current and alternate management plans, Land Economics, 72(1), pp. 113-128.

Leeworthy, V.R. \& Bowker, J.M. (1997) N onmarket Economic U ser Values of the Florida Keys/Key West, National Oceanic and Atmospheric Administration, Strategic Environmental Assessments Division (http://www-orca.nos.noaa.gov/projects/econkeys/econkeys.html).

Lindsey, G. (1999) Use of urban greenways: insights from Indianapolis, Landscape and U rban Planning, 45, pp. 145157.

Lindsey, G. \& Knaap, G. (1999) Willingness to pay for greenway projects, Journal of the American Planning Association, 65(3), pp. 297-313.

Loomis, J.B. \& Walsh, R.G. (1997) Recreation Economic Decisions: Comparing Benefits and Costs, 2nd edition (State College, PA, Venture Publishing).

McConnell, K.E. \& Strand, I. (1981) Measuring the cost of time in recreation demand analysis: applications to sport fishing, A merican Journal of Agricultural Economics, 61, pp. 153-156.

Mitchell, R.C. \& Carson, R.T. (1989) Using Surveys to Value Public Goods: The Contingent Valuation $M$ ethod (Washington, DC, Resources for the Future).

Moore, R.L., Graefe, A.R. \& Gitelson, R.J. (1994) The economic impact of rail-trails, Journal of Park and Recreation Administration, 12(2), pp. 63-72.

Morris, H. (2000) [Research Director, Rails-to-trails Conservancy, Washington, DC] Personal communication.

National Bicycle and Pedestrian Clearinghouse (1995) The Economic and Social Benefits of Off-road Bicycle and Pedestrian Facilities, National Bicycle and Pedestrian Clearinghouse Technical Brief, Technical Assistance Series, Number 2 (Washington, DC, US Department of Transportation).

National Park Service (1995) Economic Impacts of Protecting Rivers, Trails and Greenway Corridors: A Resource Book (Washington, DC, Rivers, Trails and Conservation Assistance Division).

PFK Consulting (1994) Analysis of Economic Impacts of the Northern Central Rail Trail, prepared for Maryland Greenways Commission (Annapolis, MD, Maryland Department of Natural Resources).

President's Commission on Americans Outdoors (PCAO) (1986) Report and Recommendations to the President of the U nited States (Washington, DC, US Government Printing Office).

Rails-to-trails Conservancy (RTC) (2001) (www.railtrails.org).

Randall, A. (1994) A difficulty with the travel cost method, Land Economics, 70(1), pp. 88-96.

Ribaudo, M.O. \& Epp, D.J. (1984) The importance of sample discrimination in using the travel cost method to estimate the benefits of improved water quality, land Economics, 60(4), pp. 397403.

Schreyer, R., Lime, D.W. \& Williams, D.R. (1984) Characterizing the influence of past experience on recreation behavior, journal of Leisure Research, 16(1), pp. 34-50.

Siderelis, C. \& Moore, R.L. (1995) Outdoor recreation net benefits of rail-trails, Journal of Leisure Research, 27(4), pp. 344-359.

Smith, D.S. (1993) An overview of greenways: their history, ecological context, and specific functions, in: D. S. Smith \& P. C. Hellmund (Eds) Ecology of Greenways: Design and Function of Linear Conservation Areas (Minneapolis, MN, University of Minnesota Press).

Smith, V.K. (1988) Selection and recreation demand, American Journal of Agricultural Economics, 70, pp. 29-36.

Teasley, R.J., Bergstrom, J.C. \& Cordell, H.K. (1994) Estimating revenue-capture potential associated with public area recreation, Journal of Agricultural and Resource Economics, 19(1), pp. 89-101. 


\section{C. J. Betz, J.C. Bergstrom \& J. M. Bowker}

US Census Bureau (1998) Educational Attainment of Persons 15 Years OId and Over, by Age, Sex, Race, and Hispanic Origin, March 1998 (www.census.gov).

Vaughn, W.J. \& Russell, C.S. (1982) Valuing a fishing day: an application of a systematic varying parameter model, Land Economics, 58, pp. 450463.

Woods \& Poole Economics, Inc. (1997) The Complete Economic and Demographic Data Source (Washington, DC, Woods \& Poole Economics, Inc.).

Yen, S.T. \& Adamowic, W.L. (1993) Statistical properties of welfare measures from count data models of recreation demand, Review of A gricultural Economics, 15(2), pp. 203-215.

Zawacki, W.T., Marsinko, A. \& Bowker, J.M. (2000) A travel cost analysis of nonconsumptive wildlife-associated recreation in the United States, Forest Science, 46(4), pp. 496-506. 